\title{
Assessment of Health Disparities Related Academic Preparation among Public Health Department Staff
}

\author{
Marla B. Hall ${ }^{1}$, Jeffrey J. Guidry ${ }^{2}$, E. Lisako J. McKyer ${ }^{2}$, Corliss Outley $^{2}$, Danny Ballard ${ }^{2}$ \\ ${ }^{1}$ East Carolina University, Department of Public Health, Greenville, North Carolina United States \\ ${ }^{2}$ Texas A\&M University, Department of Health \& Kinesiology, College Station, Texas, United States
}

\section{ARTICLE INFO}

Received

: 08/02/2014

Accepted : :01/07/2014

Published : :01/09/2014

\section{KEYWORD}

Health disparities

Cultural competency

Academic curriculum

\section{ABSTRACT}

Objectives: The overall goal of the research was to analyze health disparities and minority health academic preparation for individuals $(n=90)$ employed within an urban health clinic. Demographic information was collected about respondents' race, age, highest level of education and diversity training engagement. Methods: This quantitative case study utilized the Cultural Competence Assessment, which is designed to explore individual knowledge, feelings and actions of respondents when interacting with clients in health service environments. The instrument is based on the cultural competence model, and measures cultural awareness and sensitivity; cultural competence behaviors and cultural diversity experience and training. For reporting purposes, participants were divided into subgroups, clinical and non-clinical. This was completed to account for the variation in respondents' level of education, type of client/patient interaction and opportunities for professional development engagement. Results: Most respondents stated their cultural diversity training was an employer sponsored program or continuing education through a professional organization, not academic coursework. Conclusion: The data obtained illustrates the need for health organization administrators to keep their employees abreast of cultural diversity to foster an environment conducive to eliminating health disparities.

(c) Medical Education Department, School of Medical Sciences, Universiti Sains Malaysia. All rights reserved.

CORRESPONDING AUTHOR: Dr. Marla B. Hall, Assistant Professor, East Carolina University, Department of Public Health, Greenville, North Carolina, United States. Email: hallmarl14@ecu.edu

\section{Introduction}

\section{Academic Curriculum}

When factors including access, socioeconomic status and education are controlled, often racial and ethnic minorities receive lower-quality health care than white patients [1]. Scholars have identified lack of cultural competency of health professionals as having a direct link to minority health disparities [2]. Specifically, being proactive with addressing methodological challenges will contribute to the advancement of health care delivery, as it relates to best practices and improving minority health outcomes [2]. It has been suggested in addressing disparities, health care professionals must learn their roles in its elimination. However, curricula focused on diminishing and understanding health disparities, as well as accepted guidelines on content and delivery of this complex area, are lacking [1].

A study utilized surveys to assess current opportunities in health education preparational 
programs in the area of cultural competence. Academic institutions offering both undergraduate and graduate degree programs in health education were selected, by utilization of the American Association of Health Education (AAHE) Directory of Institutions [3]. The researchers obtained information on the number of courses in each program focusing on cultural competency, the percentage of capstone or core courses that integrate cultural competence, as well as the skills and content addressed in the courses. In addition, the assessment included questions regarding the level of involvement of faculty members with ethnic/racial minority groups; and their, as well as students', level of knowledge, comfort and commitment in the area [3]. The findings indicated that less than onethird of the programs offer a course devoted to cultural competency in its entirety. Eighty percent reported they do not provide cultural/diversity training or education programs for their faculty members [3].

Within another study, researchers conducted interviews with experts in cultural competency in managed care, government and academe, to assess their perspectives of the field in improving the quality of services and eliminating minority health disparities in health care [4]. Many of the informants expressed concern regarding stereotypic teaching strategies not exploring socioeconomic issues, bias and empathy. Interviewees also suggested the need for a unified conceptual teaching framework to address the current variability and quality of preparational health programs [4].

Despite the need, there are various challenges associated with teaching cultural competence to public health workers. The learners' attitude, the context, content and timing of the curriculum can act as a hindrance to practice adoption [5]. Changing attitudes and raising awareness may be complicated through some students' resistance to the discussion of social inequities and health disparities or feeling responsible for existing social issues [5]. Research suggests when discussing cultural competence, students must also be taught the concept of cultural humility. Cultural humility is defined as a process of ongoing self-reflection and critique of one's own behaviors [5]. Researchers also emphasize the need for understanding and accepting the biases of biomedical fields, in an effort to enable cross cultural dialogue and solutions [5]. Another key component in cultural competence education implementation and development is allowing the exploration of the student's own cultural values. Self-reflection is a recurring theme of the numerous approaches discussed in literature [5].

Due to the health care field encompasses a wide variety of professional disciplines and roles such as health education, social work, nursing, and physicians, a universal practicum is unlikely. However, many components of individual teaching frameworks incorporate interdisciplinary principles. The Society of General Internal Medicine Health Disparities Task Force employed a review and consensus process to develop evidence based guidelines and recommendations for health disparities curricula. Although designed for medical practitioners, the content can be applied to various health professions [1]. Authors offered three learning objectives of racial and ethnic health disparities curricula: 1) examine and understand attitudes, such as bias, mistrust, stereotyping, which practitioners and patients may bring to clinical encounters; 2) gain knowledge of the existence and severity of health disparities, including causes and solutions to elimination; and 3) acquire the effective communication skills and improve exchanges through negotiation across cultures, languages, and literacy levels. The goal of the coursework is for the learner to adopt a commitment to eliminating inequities in health care quality by understanding their professional role [1].

The Association of Schools of Public Health (ASPH) noted graduate health disparities curriculum should include the following core competencies [6]:

1. Describe the roles of history, power, privilege, and structural inequality in producing health disparities. 
2. Explain how professional ethics and practices relate to equity and accountability in diverse community settings.

3. Explain why cultural competence alone cannot address health disparities.

4. Discuss the importance and characteristics of a sustainable, diverse public health workforce.

5. Use the basic concepts and skills involved in culturally appropriate community engagement and empowerment with diverse communities.

6. Apply the principles of community-based participatory research (CBPR) to improve health in diverse populations.

7. Differentiate among availability, acceptability, and accessibility of health care across diverse populations.

8. Differentiate among linguistic competence, cultural competency, and health literacy in public health practice.

9. Cite examples of situations where consideration of culture-specific needs resulted in a more effective modification or adaptation of a health intervention.

10. Develop public health programs and strategies that respond to the diverse cultural values and traditions of the communities being served.

\section{Professional and para-professional training}

The concept of cultural competence focused continuing education for the public health workforce is stressed within the National Standards on Culturally and Linguistically Appropriate Services (CLAS). The activities and principles are designed to be integrated not only throughout health care organizations and across professional disciplines, but implemented as a partnership with the served communities [7]. There are organized themes comprised from 14 standards: Culturally Competent Care (Standards 1-3), Language Access Services (Standards 4-7), and Organizational Supports for Cultural Competence (Standards 8-14). The three types of standards are: 1) CLAS mandates which are current Federal requirements for all recipients of Federal funds (Standards 4-7). 2) CLAS guidelines or activities recommended by the Office of Minority Health \& Health Disparities (OMHD) for adoption as mandates by Federal, State, and national accrediting agencies (Standards 1-3, 8-13). 3) CLAS recommendations which are suggested by OMHD for voluntary adoption by health care organizations (Standard 14). The individual standards are shown below [7].

Standard 1: Health care organizations should ensure that patients/consumers receive from all staff member's effective, understandable, and respectful care that is provided in a manner compatible with their cultural health beliefs and practices and preferred language.

Standard 2: Health care organizations should implement strategies to recruit, retain, and promote at all levels of the organization a diverse staff and leadership that are representative of the demographic characteristics of the service area.

Standard 3: Health care organizations should ensure that staff at all levels and across all disciplines receive ongoing education and training in culturally and linguistically appropriate service delivery.

Standard 4: Health care organizations must offer and provide language assistance services, including bilingual staff and interpreter services, at no cost to each patient/consumer with limited English proficiency at all points of contact, in a timely manner during all hours of operation.

Standard 5: Health care organizations must provide to patients/consumers in their preferred language both verbal offers and written notices informing them of their right to receive language assistance services.

Standard 6: Health care organizations must assure the competence of language assistance provided to limited English proficient patients/consumers by interpreters and bilingual staff. Family and friends should not be used to provide interpretation services (except on request by the patient/consumer). 
Standard 7: Health care organizations must make available easily understood patient-related materials and post signage in the languages of the commonly encountered groups and/or groups represented in the service area.

Standard 8: Health care organizations should develop, implement, and promote a written strategic plan that outlines clear goals, policies, operational plans, and management accountability/oversight mechanisms to provide culturally and linguistically appropriate services.

Standard 9: Health care organizations should conduct initial and ongoing organizational selfassessments of CLAS-related activities and are encouraged to integrate cultural and linguistic competence-related measures into their internal audits, performance improvement programs, patient satisfaction assessments, and outcomesbased evaluations.

Standard 10: Health care organizations should ensure that data on the individual patient's/consumer's race, ethnicity, and spoken and written language are collected in health records, integrated into the organization's management information systems, and periodically updated.

Standard 11: Health care organizations should maintain a current demographic, cultural, and epidemiological profile of the community as well as a needs assessment to accurately plan for and implement services that respond to the cultural and linguistic characteristics of the service area.

Standard 12: Health care organizations should develop participatory, collaborative partnerships with communities and utilize a variety of formal and informal mechanisms to facilitate community and patient/consumer involvement in designing and implementing CLAS-related activities.

Standard 13: Health care organizations should ensure that conflict and grievance resolution processes are culturally and linguistically sensitive and capable of identifying, preventing, and resolving cross-cultural conflicts or complaints by patients/consumers.

Standard 14: Health care organizations are encouraged to regularly make available to the public information about their progress and successful innovations in implementing the CLAS standards and to provide public notice in their communities about the availability of this information.

The purpose of this research is to collect demographic data, utilizing a case study of individuals employed within an urban public health department. In order to effectively evaluate these constructs, a quantitative research approach was employed. Frequency data was collected on variables such as race, age, level of education, and diversity training participation.

\section{Method}

\section{Sample}

Within the research design, participants were identified using convenience sampling. Employees $(n=90)$ from four metropolitan clinical sites of an urban public health department, located in the southwest region of the United States, were solicited and recruited during a monthly staff meeting. This sample represents $84 \%$ of the total employees which is comprised of 107 individuals (see Table 1). Participants met criteria for inclusion in the study if they: 1) work in a clinical setting and 2) provide services to individuals of racial and ethnic minority backgrounds. Participants included health education specialists, nurses, physicians, social workers, dental practitioners and other general staff. For reporting purposes, participants were divided into subgroups, clinical and non-clinical (clerical staff). This was completed to account for the variation in respondents' level of education, type of client/patient interaction and opportunities for professional development engagement. 
Table 1: Total employees from potential sample pool

\begin{tabular}{|c|c|c|}
\hline Clinic & Number of Staff & $\begin{array}{l}\text { Racial Description } \\
\text { of Majority Clients } \\
\text { Served (i.e, } \\
\text { Hispanic, Black, } \\
\text { etc.) }\end{array}$ \\
\hline 1 & $\begin{array}{l}\text { Administrators: } 2 \\
\text { Clerical: } 6 \\
\text { Social Workers: } 0 \\
\text { Nurses: } 10 \\
\text { Physicians: } 2 \\
\text { Health Educators: } 0 \\
\text { Other: } \\
\text { CMA/CA: } 5 \\
\text { CRS: } 1\end{array}$ & Hispanic \\
\hline 2 & $\begin{array}{l}\text { Administrators: } 2 \\
\text { Clerical: } 6 \\
\text { Social Workers: } 0 \\
\text { Nurses: } 11 \\
\text { Physicians: } 2 \\
\text { Nurse Practitioner: } 1 \\
\text { Health Educators: } 0 \\
\text { Other: } \\
\text { Community Relation } \\
\text { Specialist: } 1 \\
\text { Eligibility Clerk: } 1\end{array}$ & $\begin{array}{l}\text { African American } \\
\text { and Hispanic }\end{array}$ \\
\hline 3 & $\begin{array}{l}\text { Administrators: } 2 \\
\text { Clerical: } 4 \\
\text { Social Workers: } 0 \\
\text { Nurses: } 5 \\
\text { Physicians: } 1 \\
\text { Health Educators: } 0 \\
\text { Other: } \\
\text { MSC Personnel: } 7 \\
\text { Programming Team: } 4\end{array}$ & $\begin{array}{l}\text { African American } \\
\text { and Hispanic }\end{array}$ \\
\hline 4 & $\begin{array}{l}\text { Administrators: } 4 \\
\text { Clerical: } 6 \\
\text { Social } \\
\text { Workers/Counselors: } 0 \\
\text { Nursing Staff: } 4 \\
\text { Physicians: } 11 \\
\text { Health Educators: } 2 \\
\text { Other: } \\
\text { Community Nurses: } 0 \\
\text { Community Specialist: } \\
2 \text { Community Liaison: } 0 \\
\text { Navigators: } 0 \\
\text { Dental Assistance: } 3 \\
\text { Dentist: } 2\end{array}$ & $\begin{array}{l}\text { African American } \\
\text { and Hispanic }\end{array}$ \\
\hline
\end{tabular}

\section{Assessment Tool}

The Cultural Competence Assessment (CCA) is designed to explore individual-level knowledge, feelings and actions of respondents when interacting with others in health service environments [8]. The instrument is based on the cultural competence model, and measures cultural awareness and sensitivity; cultural competence behaviors, cultural diversity experience and training on a 49 item scale. It seeks to assess actual behaviors through a self report, rather than self-efficacy of performing behaviors [9].
Cultural awareness and sensitivity is analyzed with the Cultural Awareness and Sensitivity (CAS) subscale which measures with a 5-point likert-like response. An assessment of cultural competence behaviors is measured by the Cultural Competence Behaviors (CCB) subscale, with response categories of always, often, at times, never, and not sure [9]. A single-item index is used for cultural diversity experience with respondents being asked about the amount of various encounters with minority groups within the past year. Subscale scores are provided by adding the CAS and CCB totals [9]. Higher scores indicate more positive attitudes, a higher level of knowledge and increased engagement of competence behaviors. In addition, CCA assesses self identified ethical/racial group, age and education [9].

A convenience sample of 405 healthcare providers were recruited from hospitals, home health agencies and community health agencies, to research CCA reliability and validity among the population. Content and face validity for the instrument was established and the internal consistency was documented at .92. Cronbach's alphas for CAS and CCB subscales were reported at .75 and .93 , respectively [9]. The psychometric analysis of CCA suggests it is an effective tool to measure cultural competence. It is useful to evaluate healthcare professionals' specific cultural competence training needs which may decrease health disparities [9].

The Cultural Competence Behaviors (CCB) subscale tool was used in a study to determine if there is an association between cultural competence of primary care providers and the clinics in which they are employed [10]. Fortynine providers, from twenty-three clinics responded to the online survey, across two states. The researchers suggested providers with who possess attitudes which reflect increased cultural learning motivation, are more likely to work in clinics which offer diversity training and cultural competent patient education materials [10].

Within another study, the CCA assessment evaluated the cultural competence of thirty-one public health nurses. In addition, participants 
documented personal experiences and perceptions of culturally competent healthcare through qualitative data collection [11]. The findings concluded participation in specific types of training were highly correlated to cultural competence knowledge and attitudes. Many reported increased levels of cultural competency knowledge and beliefs; however they disclosed the need for diversity education opportunities to enable favorable clinical application [11]. This manuscript focuses solely on the diversity training experience and demographics collection aspects of the assessment tool.

\section{Result}

Of the sixty-two clinical respondents, $47 \%$ were African American, 44\% Hispanic/Latino and 5\% Caucasian. This was comparable to the nonclinical subgroup with $43 \%$ being comprised of African Americans, 50\% Hispanic/Latino and $7 \%$ of the total population self-identifying as Caucasian (see Table 2). In addition, respondents reported high levels of interaction with patients from ethnic and racial minorities (see Table 3). Almost the entire sample pool interacted with patients from Hispanic/Latino heritage. Eightysix percent of respondents encountered Black/African American individuals within their position of employment. Over half of the employees examined served Caucasian and Asian community members. In addition, $41 \%$ of those surveyed noted Arab Americans/Middle Easterners as their usual clientele. Respondents were asked about their knowledge of CLAS adherence and over two-thirds of both subgroups were not sure if their clinic of employment implemented some of the recommended standards (see Table 2). Observing the clinical and non-clinical respondents, approximately $47 \%$ and $57 \%$ respectively, stated their cultural diversity training was an employer sponsored program.

Table 2: Demographic characteristics of sample

\begin{tabular}{|c|c|c|}
\hline Variable & $\begin{array}{l}\text { Clinical } \\
\text { Staff } \\
(n=62)\end{array}$ & $\begin{array}{l}\text { Non- } \\
\text { clinical } \\
\text { Staff } \\
(n=28)\end{array}$ \\
\hline Age (in years), mean (SD) & $51(10.8)$ & $46[9.3]$ \\
\hline \multicolumn{3}{|l|}{ Highest education level (\%) } \\
\hline Less than high school & 2 & 0 \\
\hline Diploma & 15 & 22 \\
\hline High school or GED & 27 & 48 \\
\hline Associate degree & 21 & 15 \\
\hline Bachelors degree & 13 & 7 \\
\hline $\begin{array}{l}\text { Graduate or professional } \\
\text { degree }\end{array}$ & 21 & 7 \\
\hline \multicolumn{3}{|l|}{ Racial/ethnic self-identification (\%) } \\
\hline Black/African American /Negro & 47 & 43 \\
\hline Hispanic/Latino & 44 & 50 \\
\hline White/Caucasian/European American & 5 & 7 \\
\hline Asian & 2 & 0 \\
\hline Other & 2 & 0 \\
\hline \multicolumn{3}{|l|}{ Knowledge of CLAS standards (\%) } \\
\hline Yes & 28 & 15 \\
\hline No & 2 & 8 \\
\hline Not Sure & 70 & 77 \\
\hline \multicolumn{3}{|l|}{ Position within agency (\%) } \\
\hline LPN & 14 & 0 \\
\hline $\mathrm{RN}$ & 24 & 0 \\
\hline Clerical Worker & 0 & 96 \\
\hline Dental Practitioners & 18 & 0 \\
\hline Physician & 3 & 0 \\
\hline Certified Medical Assistant & 20 & 0 \\
\hline Other & 22 & 4 \\
\hline
\end{tabular}

Table 3: Racial composition of racial/ethnic patients encountered within the past 12 months

\begin{tabular}{lc}
\hline Patients' Racial Composition & $\begin{array}{c}\text { Percentage of respondents } \\
\text { with interaction }\end{array}$ \\
\hline Hispanic/Latino (including Mexican, Mexican American, Chicano, Puerto Rican, Cuban, other Spanish) & 99 \\
\hline White/Caucasian/European American & 55 \\
\hline Black/African American/Negro & 86 \\
\hline American Indian/Alaska Native & 15 \\
\hline Asian (Asian Indian, Chinese, Filipino, Japanese, Korean, Vietnamese, or other Asian) & 52 \\
\hline Native Hawaiian/pacific Islander & 10 \\
\hline Arab American/Middle Eastern & 41 \\
\hline
\end{tabular}

Continuing education offered training was reported among clinical workers at roughly $24 \%$ and $35 \%$ for non-clinical staff (see Table 4). When assessing respondents with diversity training preparational behaviors, clinical workers sought out information on cultural needs when identifying new individuals in the work environment more often than their non-clinical coworkers. Clinical respondents also had a better understanding of the variance in the definition of "health care" by patients from racial and ethnic minority backgrounds (see Table 5). 
Table 4: Diversity training engagement of respondents

\begin{tabular}{lcccc}
\hline Type of Diversity Training & \multicolumn{2}{c}{ Clinical } & \multicolumn{2}{c}{ Non-Clinical } \\
\cline { 2 - 5 } & $\mathbf{N}$ & $\mathbf{N}$ & $\mathbf{\%}$ \\
\hline Content Covered in a College Course & 1 & 2.22 & 0 & 0 \\
\hline Professional Conference or Seminar & 4 & 8.89 & 2 & 8.70 \\
\hline Employer Sponsored Program & 21 & 46.67 & 13 & 0 \\
\hline On-line (Computer Assisted) Education & 5 & 11.11 & 8 & 34.78 \\
\hline Continuing Education Offering & 11 & 24.44 & 0 \\
\hline Other & 3 & 6.67 & 0 \\
\hline
\end{tabular}

Table 5: Effects of diversity training on employee preparational activities by percentage

\begin{tabular}{|c|c|c|c|c|c|c|}
\hline & \multicolumn{2}{|c|}{$\begin{array}{l}\text { Aspects of cultural diversity } \\
\text { need to be assessed for each } \\
\text { individual, group, and } \\
\text { organization. }\end{array}$} & \multicolumn{2}{|c|}{$\begin{array}{l}\text { If I know about a person's } \\
\text { culture, I don't need to assess } \\
\text { their personal preferences for } \\
\text { health services. }\end{array}$} & \multicolumn{2}{|c|}{$\begin{array}{l}\text { I understand that people from } \\
\text { different cultures may define } \\
\text { the concept of "healthcare" in } \\
\text { different ways. }\end{array}$} \\
\hline & Clinical & Non-Clinical & Clinical & Non-Clinical & Clinical & Non-Clinical \\
\hline Strongly Agree & 12 & 13 & 4 & 0 & 27 & 26 \\
\hline Agree & 54 & 17 & 10 & 0 & 61 & 44 \\
\hline Somewhat Agree & 18 & 30 & 2 & 9 & 8 & 22 \\
\hline Neutral & 6 & 26 & 12 & 9 & 4 & 0 \\
\hline Somewhat Disagree & 4 & 0 & 10 & 22 & 0 & 0 \\
\hline Disagree & 4 & 13 & 37 & 43 & 0 & 4 \\
\hline Strongly Disagree & 0 & $\mathrm{X}$ & 25 & 17 & 0 & 0 \\
\hline \multirow[t]{3}{*}{ No Opinion } & 2 & $\mathrm{X}$ & 0 & 0 & 0 & 4 \\
\hline & \multicolumn{2}{|c|}{$\begin{array}{l}\text { I seek information on } \\
\text { cultural needs when I } \\
\text { identify new people in my } \\
\text { work or school. }\end{array}$} & \multicolumn{2}{|c|}{$\begin{array}{l}\text { I use resource books and other } \\
\text { materials available to help me } \\
\text { learn about people from } \\
\text { different cultures }\end{array}$} & \multicolumn{2}{|c|}{$\begin{array}{l}\text { I use a variety of sources to } \\
\text { learn more about the cultural } \\
\text { heritage of other people. }\end{array}$} \\
\hline & Clinical & Non-Clinical & Clinical & Non-Clinical & Clinical & Non-Clinical \\
\hline Always & 8 & 5 & 6 & 0 & 10 & 0 \\
\hline Very Often & 20 & 9 & 14 & 4 & 17 & 14 \\
\hline Somewhat Often & 8 & 14 & 4 & 9 & 13 & 9 \\
\hline Often & 12 & 5 & 14 & 14 & 17 & 18 \\
\hline Sometimes & 25 & 18 & 22 & 23 & 19 & 18 \\
\hline Few Times & 4 & 5 & 14 & 4 & 8 & 9 \\
\hline Never & 20 & 45 & 18 & 41 & 14 & 31 \\
\hline Not Sure & 2 & $\mathrm{X}$ & 6 & 5 & 2 & 0 \\
\hline
\end{tabular}

\section{Discussion}

The health care field encompasses a wide variety of professional disciplines such as administrative, oral health practitioners, nursing, and physicians, making a universal cultural competency practicum unlikely. However, as illustrated within the data collected, employer sponsored diversity training is a crucial strategy in addressing workforce deficiencies and building the capacity of employees. Culturally focused training opportunities for professionals are usually referred to as cultural diversity/competence training or cultural sensitivity training. Although the terms are often used interchangeably, there are notable differences. From a public health perspective cultural sensitivity involves being aware of cultural differences and similarities, and its effect on individuals' values, learning and behavior [12]. Within public health the components of cultural sensitivity include: 1) willingness to adapt one's communication and behaviors to be compatible with another culture's norms and; 2) willingness to learn about the traditions and characteristics of other cultures [12].

However, cultural diversity training typically incorporates a more holistic approach going beyond psycho-emotional factors or intent, into action. It has elements of cultural sensitivity, humility, relevance and self awareness. Researchers noted these types of comprehensive training and education improves employee relations and enhances interpersonal skills in various areas [13]. It assists workers improve their performance by fostering an environment free of bias and stereotypes. Diversity training 
implements techniques to foster the discovery of self initiated behaviors that could create a workplace which is conducive to improving the health outcomes of those being served [13].

Depending upon an individual's career discipline, such as clerical workers, there may not be a professional organization in their field to gain cultural competence continuing education. In addition, those without post-secondary degrees may be less inclined to participate in certifications offered through collegiate institutions. This illustrates the importance of employer sponsored programs to reach these populations. Often times these trainings are conducted during working hours and in convenient locations, enabling employee participation.

The concept of cultural competency focused continuing education for the public health workforce is stressed within the National Standards on Culturally and Linguistically Appropriate Services (CLAS). Most health care organizations receiving federal dollars must adhere to the recommendations for accreditation purposes. Within both subgroups, clinical and non-clinical workers, over two-thirds of the respondents were not sure if their clinic implemented these strategies. CLAS is designed to be integrated throughout an organization and undertaken in partnership with the communities being served. All employees, no matter their role within the organization, hold some degree of responsibility when addressing these standards. It must be incorporated within the daily operational plans. Administrators and executives are obligated in keeping their employees abreast of this information to assist in a collective effort, to ensure maximum effectiveness. This coupled with cultural diversity training may foster an environment conducive to eliminating health disparities.

\section{Reference}

1. Smith WR, Betancourt JR, Wynia MK, Bussey-Jones J, Stone VE, Phillips CO, Fernandez A, Jacobs E, Bowles J. Recommendations for teaching about racial and ethnic disparities in health and health care. Ann Intern Med. 2007;147(9):654-65.

2. Bushy A. Conducting culturally competent rural nursing research. Annu Rev Nurs Res. 2008;26(1):221-36.

3. Luquis R, Pèrez MA, Young K. Cultural competence development in health education professional preparation programs. Am J Health Educ. 2006;37(4):233-41.

4. Betancourt JR, Green AR, Carrillo JE, Park ER. Cultural competence and health care disparities: key perspectives and trends. Health Affair. 2005;24(2):499-505.

5. Boutin-Foster C, Foster JC, Konopasek L. Viewpoint: physician, know thyself: the professional culture of medicine as a framework for teaching cultural competence. Acad Med. 2008;83(1):106-11.

6. Association of Schools of Public Health. (2009). Schools of public health goals towards eliminating racial and ethnic health disparities. Washington, DC. Available from:

http://www.asph.org/healthdisparitiesreport/ Diversity.cfm.

7. Office of Minority Health \& Health Disparities. (2007). National standards on culturally and linguistically appropriate services. Washington, DC: Department of Health and Human Services. Available from: http://minorityhealth.hhs.gov/templates/bro wse.aspx? $l v l=2 \& l v l I D=15$.

8. Schim S. (2009). Cultural competence survey. Detroit, MI: Wayne State University.

9. Doorenbos AZ, Schim SM, Benkert R, Borse NN. Psychometric evaluation of the cultural competence assessment instrument among healthcare providers.

Nurs Res. 2005;54:324-31.

10. Paez KA, Allen JK, Carson KA, Cooper LA. Provider and clinic cultural competence in a primary care setting. Soc Sci Med. 2008;66(5):1204-16.

11. Starr S, Wallace DC. Self-Reported Cultural Competence of Public Health Nurses in a Southeastern US Public Health Department. Public Health Nurs. 2009;26(1):48-57.

12. Stafford JR, Bowman R, Ewing T, Hanna J, Lopez-DeFede A. Building cultural bridges. Bloomington, IN: National Educational Service; 1997.

13. Scott S. (2012). Cultural diversity training \& education in the workplace. Houston, TX: Houston Chronicles. Available from: http://smallbusiness.chron.com/culturaldiversity-training-education-workplace1853.html. 